\title{
Editorial \\ Genetic control of disease in an experimental model for Sjögren's syndrome
}

\author{
Åsa Andersson
}

Department of Pharmacology and Pharmacotherapy, Faculty of Pharmaceutical Sciences, Copenhagen University, Universitetsparken 2 , DK-2100 Copenhagen $\varnothing$, Denmark

Corresponding author: Åsa Andersson, aaa@farma.ku.dk

Published: 20 January 2009

Arthritis Research \& Therapy 2009, 11:102 (doi:10.1186/ar2583)

This article is online at http://arthritis-research.com/content/11/1/102

(c) 2009 BioMed Central Ltd

See related research by Nguyen et al., http://arthritis-research.com/content/10/6/R137

\begin{abstract}
Sjögren's syndrome is an autoimmune disease with a complex etiology depending on hereditary and environmental factors. The disease is characterized by lymphocytic infiltration and inflammation in the salivary and lacrimal glands, leading to oral and ocular dryness. To understand the genetic susceptibility in Sjögren's syndrome, studies of disease phenotypes have been performed in the non-obese diabetic (NOD) mouse. By the identification of genetic regions controlling development of autoimmune exocrinopathy in the NOD mouse and by reducing one of these regions considerably, Nguyen et al. in a recent issue of Arthritis Research and Therapy propose candidate genes for development of Sjögren's syndrome.
\end{abstract}

Susceptibility to autoimmune diseases is dependent on multiple genes, of which most contribute minor effects that precipitate the disease when expressed in the right environmental context. The rationale behind studies of genetics in complex diseases is that identification of gene variants contributing to susceptibility will provide important information concerning the pathogenesis and hopes for future therapy. Experimental animal models are used to address hereditary factors of complex human diseases. The genetics and the environment can be carefully controlled in such models and the number of siblings is high enough to allow for the identification of statistically significant genetic linkage.

In a recent issue of Arthritis Research and Therapy, Nguyen et al. [1] report the fine mapping of a genetic region important for development of disease in a mouse model for Sjögren's syndrome ( $\mathrm{SjS}$ ). The experimental model was derived from the non-obese diabetic (NOD) mouse, a model for type 1 diabetes. In addition to inflammation of the pancreatic islets of Langerhans, these mice show infiltration of mononuclear cells in the salivary and lacrimal glands.
A number of genetic associations have been reported from studies of SjS in humans [2]. In contrast to other autoimmune diseases, there is no clear dependence on the human leukocyte antigen (HLA) haplotype for susceptibility to SjS. This is supported by studies in the NOD mouse where the $\mathrm{MHC}$ haplotype, essential for development of type 1 diabetes, can be exchanged with a diabetes non-susceptible $\mathrm{MHC}$ without preventing development of an SjS-like disease [3].

Genetic studies of type 1 diabetes in the NOD mouse have revealed a number of genetic intervals ( $/ d d s$ ) linked to disease development. For further studies, important genetic regions have been bred from the NOD mouse into other strains, to generate mice that are congenic for different $/ d d$ regions.

The authors previously described two genetic loci, autoimmune exocrinopathy 1 (Aec1) on chromosome 3 (from Idd3) and Aec2 on chromosome 1 (from /dd5). When Aec1 and Aec2 were bred into the C57BI/6 mouse, which is resistant to autoimmune diabetes and exocrinopathy, the SjSlike disease was manifested in these congenic C57BI/6.NODAec1Aec2 mice [4]. This study showed that Aec1 and Aec2 contain genes that control development of $\mathrm{SjS}$.

In the present study, the investigators produced recombinant inbred lines by crossing the C57BI/6 and C57BI/6.NODAec1Aec2 strains. A recombinant inbred line is derived from two strains of mice that are intercrossed for many generations in order to obtain mice carrying chromosomal fragments from the parental strains randomly distributed in the genome. Starting with $\mathrm{C} 57 \mathrm{BI} / 6$ and the C57BI/6.NODAec1Aec2 congenic strain, the gene segregation was confined to the Aec1 and Aec2 regions. In this way, the authors generated recombinant inbred strains with over-

$\mathrm{cM}=$ centiMorgan; $\mathrm{NOD}=$ non-obese diabetic $; \mathrm{SjS}=$ Sjögren's syndrome . 
lapping Aec2 intervals. The recombinant inbred mice were subsequently investigated for SjS disease phenotypes: saliva production, sialadenitis, and anti-nuclear antibodies. By this strategy, the critical genetic interval, containing a gene (or genes) controlling the disease traits, could be reduced from approximately 70 to 10 centiMorgans (cM), located $80 \mathrm{cM}$ from the centromere on chromosome 1 [1].

Dissections of disease loci in models for autoimmune diseases have shown that one locus can contain more than one gene linked to disease $[5,6]$. In one study, a locus of approximately $20 \mathrm{cM}$ contained four sub-loci controlling disease [6]. Thus, it is possible that the re-defined Aec2 locus contains more than one gene involved in the disease process.

The shorter Aec2 interval on mouse chromosome 1 includes loci that are linked to the development of autoimmune disease in mouse models: Eae27 (experimental autoimmune encephalomyelitis 27); Stia1 (serum transfer induced arthritis 1); Mbis 1 (mycobacterium-induced systemic lupus erythematosus 1). This might suggest shared disease pathways in different models for autoimmune diseases controlled by the same genes within this interval.

On the basis of potential candidate genes located within the re-defined Aec2 interval, the authors elegantly discuss possible disease pathways. One pathway starts out from the Tnfsf4 gene encoding the OX40 ligand (OX40L). This molecule negatively influences the activity of type 1 regulatory $\mathrm{T}$ cells $[7,8]$, thereby possibly contributing to autoimmunity. The other pathway discussed is based on genes within the Aec2 locus, important in the homeostasis of lipids, lipoproteins, cholesterols, and fatty acids. Secondary effects of impaired lipid homeostasis could result in inflammation and cell death. Results from a recent gene-expression study support a role for these genes in autoimmune exocrinopathy [9].

Although the re-defined genetic interval has been considerably reduced compared to the original Aec2 locus, it still contains approximately fifty genes. Without direct data on candidate gene expression in tissues from mice with the smaller Aec2 interval, or investigations of polymorphism in, or close to, candidate genes from susceptible and resistant mouse strains, speculations on disease mechanisms has to be considered preliminary. The re-defined Aec2 locus could most likely be further reduced by a new breeding program and investigated for genetic variants influencing development of SjS.

\section{Competing interests}

The author declares that they have no competing interests.

\section{References}

1. Nguyen CQ, Cornelius JG, Cooper L, Neff J, Tao J, Lee BH, Peck $A B$ : Identification of possible candidate genes regulating Sjögren's syndrome-associated autoimmunity: a potential role for TNFSF4 in autoimmune exocrinopathy. Arthritis Res Ther 2008, 10:R137.
2. Williams $\mathrm{PH}$, Cobb BL, Namjou B, Scofield RH, Sawalha $A H$, Harley JB: Horizons in Sjögren's syndrome genetics. Clin Rev Allergy Immuno/ 2007, 32:201-209.

3. Robinson CP, Yamachika S, Bounous DI, Brayer J, Jonsson R, Holmdahl R, Peck AB, Humphreys-Beher MG: A novel NODderived murine model of primary Sjögren's syndrome. Arthritis Rheum 1998, 41:150-156.

4. Cha S, Nagashima H, Brown VB, Peck AB, Humphreys-Beher MG: Two NOD Idd-associated intervals contribute synergistically to the development of autoimmune exocrinopathy (Sjögren's syndrome) on a healthy murine background. Arthritis Rheum 2002, 46:1390-1398.

5. Johannesson $M$, Karlsson J, Wernhoff $P$, Nandakumar $K S$, Lindqvist AK, Olsson L, Cook AD, Andersson $\AA$, Holmdahl R: Identification of epistasis through a partial advanced intercross reveals three arthritis loci within the Cia5 QTL in mice. Genes Immun 2005, 6:175-185.

6. Karlsson J, Johannesson M, Lindvall T, Wernhoff P, Holmdahl R, Andersson $\AA$ : Genetic interactions in Eae2 control collageninduced arthritis and the CD4+/CD8+ T cell ratio. J Immunol 2005, 174:533-541.

7. Ito $\mathrm{T}$, Wang $\mathrm{YH}$, Duramad $\mathrm{O}$, Hanabuchi $\mathrm{S}$, Perng OA, Gilliet $\mathrm{M}$, Qin FX, Liu YJ: OX40 ligand shuts down IL-10-producing regulatory T cells. Proc Natl Acad Sci USA 2006, 103:1313813143.

8. Takeda I, Ine S, Killeen N, Ndhlovu LC, Murata K, Satomi S, Sugamura K, Ishii N: Distinct roles for the OX40-OX40 ligand interaction in regulatory and nonregulatory $\mathrm{T}$ cells. J Immunol 2004, 172:3580-3589.

9. Killedar SJ, Eckenrode SE, Mclndoe RA, She JX, Nguyen CO, Peck AB, Cha S: Early pathogenic events associated with Sjögren's syndrome (SjS)-like disease of the NOD mouse using microarray analysis. Lab Invest 2006, 86:1243-1260. 